\title{
Sebuah Pandangan Komprehensif akan Normative Marketing Ethics
}

\author{
Budi Setiawan \\ Dosen Program Studi Manajemen STIE Kesatuan \\ budisetiawan@stiekesatuan.ac.id
}

\begin{abstract}
Abstrak
Pandangan filosofis dari marketing ethics bersifat normatif, berfokus pada nilai, dan terkait dengan pembenaran mengapa standar etika tertentu dapat diimplementasikan pada suatu praktek tertentu dan alasan yang mendasarinya. Diskusi terkait ethics dari pandangan positif lebih dominan dibandingkan dari pandangan normatif, sehingga menciptakan gap yang menjadi penting untuk didiskusikan lebih lanjut. Artikel ini berusaha membahas sebuah pandangan komprehensif akan normative marketing ethics dalam konteks umum, maupun dalam konteks pemasaran internasional. Dalam upaya memberikan wawasan yang lebih menyeluruh terkait ethics, maka didiskusikan pula ethics dalam sudut pandang konsumen.
\end{abstract}

Keywords: Ethics, Marketing ethics, Normative marketing ethics, Consumer ethics

\section{Pendahuluan}

Ethics sebagai sebuah cabang penting dari filosofi yang berfokus pada moral dan nilai, secara luas mencakup sebuah konsep mengenai benar atau salah, baik atau jahat, kebajikan atau keburukan, dan bertanggung jawab dengan cara ini. Nilai memberikan pedoman standar seseorang dalam menentukan baik atau buruk. Sedangkan moral adalah sebuah pola dari pemikiran, tindakan, dan keputusan yang berlaku dalam kehidupan sehari-hari (Javalgi \& Russell, 2018). Marketing Ethics menurut Laczniack \& Murphy (2018) dapat dipahami sebagai sebuah studi sistematis tentang bagaimana suatu standar moral diterapkan pada pengambilan keputusan, perilaku, dan seluruh institusi pemasaran. Marketing ethics mengacu pada sebuah praktek marketing yang menekankan pada transparansi, terpercaya, personel yang bertanggung jawab, dan/atau aksi maupun kebijakan organisasi pemasaran yang menunjukkan integritas serta keadilan pada konsumen dan stakeholder lainnya (Murphy et al, 2017). Sebagai sebuah studi, Marketing ethics berasal dari dua bidang ilmu yang berbeda, yakni filosofis dan social science. Pandangan filosofis bersifat normatif dan berfokus pada nilai, terkait pembenaran mengapa standar etika tertentu dapat diimplementasikan pada suatu praktek tertentu dan mengartikulasikan alasan-alasannya. Sedangkan social science bersifat positivistic yang menggambarkan apa yang sebenarnya nampak terjadi dalam situasi bermuatan moral, berdasarkan pengamatan atau data empiris. Laczniack \& Murphy (2018) menyatakan bahwa positive ethics lebih mendominasi pada publikasi artikel di jurnal ilmiah, dibandingkan normative ethics. Beberapa akademisi Marketing berpendapat bahwa konten dan proses dari marketing science adalah objective dan value-neutral, sehingga cenderung berusaha untuk menghindari perspektif normatif dan lebih prefer pada perspektif positif. Hal ini menyebabkan adanya gap yang secara substantif penting untuk dapat dikaji lebih komprehensif, sebagai upaya memberi kontribusi pemahaman konseptual yang positif. 


\section{Normative Marketing Ethics}

Berfokus pada perspektif normative ethics, maka marketer akan berusaha mencari tahu, mengapa praktek Marketing ethics ini menjadi penting dan mengapa para praktisi pemasaran harus menerapkan strategi ini pada pengambilan keputusan untuk memecahkan masalah. Marketer memposisikan marketing ethics pada ranah strategis dalam upaya mencapai kesuksesan secara finansial di bottom line, atau dengan kata lain we doing ethics for finansial reason, dikarenakan customer kita ternyata juga concern akan hal tersebut. Marketer menerapkan ME sebagai sebuah additional value yang akan menjadi pertimbangan bagi para customers to choose our product, sehingga marketing ethics adalah suatu instrumental bagi marketer untuk mendapatkan profit.

Para ahli di bidang normative ethics menjelaskan bahwa terdapat empat jenis normative ethics, yakni:

\section{Consequentialism (Teleological evaluation)}

Keputusan pemasaran merupakan sesuatu yang etis maupun tidak etis, berdasarkan pada konsekuensi atau outcome-nya (Laczniack \& Murphy, 2018). Artinya, jika keputusan yang diambil dinilai akan menghasilkan konsekuensi yang lebih baik bagi marketer (perusahaan), maka hal itu adalah etis. Hunt (2018) menjelaskan bahwa seseorang yang melakukan identifikasi alternatif pengambilan keputusan terkait ethical problem melalui Teleological evaluation, maka akan memprediksi probilitas dari konsekuensinya, kepentingannya bagi stakeholder, dan desirability-nya akan konsekuensi tersebut.

\section{Duty-based ethics (deontological norms)}

Sederhananya, Laczniack \& Murphy (2018) menjelaskan bahwa Marketer harus melakukan hal tersebut karena memang sesuai aturan atau regulasi yang ada dan berlaku, sehingga faktor pendorong atau motivasinya adalah bukan pada konsekuensi, tetapi pada pelaksanaan tugas sesuai peraturan. Hunt (2018) menjelaskan bahwa dalam proses evaluasi deontology, seseorang (dalam hal ini Marketer) akan melakukan evaluasi benar/salah dari setiap alternatif perilaku, membandingkannya dengan norma-norma deontology (hypernorms sebagai sebuah norma universal yang mencerminkan prinsip-prinsip fundamental keberadaan manusia; dan norma lokal yang secara konteksnya spesifik dan berbasis pada masyarakat) yang telah ditentukan sebelumnya.

\section{Contract-based morality}

Rawls (1971) dalam Laczniack \& Murphy (2018) merekomendasikan dua prinsip utama yang tidak boleh dilanggar terkait Contract-based morality, yakni Kebebasan dan Keadilan. Sehingga dalam melakukan transaksi dengan siapapun, maka Marketer harus adil, tidak boleh membeda-bedakan atau melihat masa lalu seseorang. Hal ini dikarenakan setiap orang memiliki hak-hak dasar dan Marketer harus menyikapinya secara adil. Sehingga berbicara mengenai ethics (di dalam finance disebut dengan governance), tentunya Marketer harus memenuhi aspek-aspek moralitas. 


\section{Virtue ethics}

Fokus utamanya adalah pada pengambil keputusan (misalnya: manajer), bukan kepada hasil keputusannya. Dengan kata lain, individu pengambil keputusan dan kualitas karakternya memiliki peranan paling utama dalam etika, bukan sekedar analisis keputusan yang akan dibuat. Kebajikan merupakan kebiasaan baik yang harus dipraktekkan dan dipelajari dengan melihat dan meniru perilaku dari mentor sebagai role model-nya. Terkait mentor, kiranya juga perlu hati-hati dalam memilih mentor atau orang-orang yang dijadikan panutan.

Kajian lebih lanjut mengenai normative marketing ethics (why we doing or why we are not doing of ethics) dan hubungan pelanggan dengan merk, menurut Laczniack \& Murphy (2018), akan cenderung mengarah pada relationship marketing, sustainable consumption and marketing, digital marketing and privacy (terkait pengambilan/penggunaan data digital konsumen), interface antara Corporate social responsibility/CSR dan marketing ethics (di mana marketing ethics lebih dari sekedar CSR, karena marketing ethics is more than society, yakni seluruh stakeholder), stakeholder orientation (fokus pada pandangan pro-society dan pro-environment), power and responsibility in the channel (fokus pada korporasi dan strategik), serta isu-isu terkait Base of the Pyramid atau orang-orang (konsumen) miskin.

\section{Normative Marketing Ethics dalam Konteks Pemasaran Internasional}

Dalam konteks pemasaran internasional, Javalgi \& Russell (2018) menjelaskan bahwa ethics akan terkait dengan cross-culture, sehingga Marketer tentu akan berhadapan dengan culture yang berbeda-beda antara negara satu dengan negara lainnya. Dengan demikian, suatu keputusan yang diambil di suatu wilayah/lokasi geografi tertentu, belum tentu bisa langsung di-copy paste ke wilayah/negara lain, dikarenakan aspek ethics-nya berbeda sehingga adopsinya pun akan berbeda. Culture memiliki peran yang penting dalam mempengaruhi persepsi etis individu, pengambilan keputusan, dan sikap seseorang, sehingga industri harus mewaspadai dan mempertimbangkan dengan seksama akan perbedaan budaya. Perbedaan budaya antar-negara, akan berpotensi menciptakan berbagai dilema terkait etika. Dengan demikian, Marketer tidak boleh mengasumsikan bahwa standar etika dari dua negara itu sama, meskipun budaya kedua negara tersebut nampak mirip. Desain logo, nama merek, pemilihan warna, content, maupun pemilihan diksi, yang well-accepted di suatu negara, belum tentu juga akan accepted di negara lain. Mempekerjakan orang tua di suatu negara, bisa jadi dilarang di negara lain, demikian juga sebaliknya agar orang tua tersebut tidak pikun (bukan sebagai penyandang ekonomi). Beda negara, maka akan beda pula need and wantsnya. Maka alternatif strategi yang bisa diterapkan, di antaranya adalah: (1) standardized, yakni di mana satu strategi di home country diterapkan pada semua host country; (2) localized, di mana strategi disesuaikan pada setiap host country; dan (3) globalized, yakni menetapkan suatu standar di suatu negara yang akan melayani beberapa negara lainnya dalam kawasan.

\section{Ethics dalam Perspektif Konsumen}

Marketing ethics merupakan perspektif ethics dalam sudut pandang perusahaan, sedangkan apabila dilihat dari sudut pandang konsumen, maka dikenal dengan istilah Consumer ethics. 
Carlos et al (2018) menjelaskan bahwa consumer ethics (atau dalam banyak literatur disebut dengan ethical consumer), menggambarkan orang-orang (consumer) yang mempertimbangkan lingkungan, kesejahteraan manusia dan/atau hewan, sebagai sesuatu yang penting. Sebagai konsekuensinya, consumer akan mengevaluasi gaya hidup konsumsinya dengan mempertimbangkan beragam isu tersebut. Consumer ethics berfokus pada bagaimana konsumen mempersepsikan dan bereaksi terhadap sebuah situasi pembelian yang berpotensi melanggar etika. Dalam memilih produk, konsumen juga bisa mempersepsikan bahwa ketika suatu produk ternyata selaras dengan nilai dirinya, maka akan memilih produk dari perusahaan yang dianggap lebih etis dibandingkan memilih produk dari perusahaan lain.

Misal pada kasus sebuah perusahaan yang dianggap pro LGBT, produk yang harmful bagi lingkungan, atau isu produk yang diproduksi dari negara kapitalis, maka konsumen dapat melakukan sebuah "moral boycot atau negative buying". Sedangkan pada perusahaan yang dianggap lebih etis, maka konsumen dapat melakukan "positive buying atau memberikan dukungan". Carlos et al (2018) menyatakan terdapat dimensi perspektif identitas moral dan spiritualitas, yang akan berdampak pada bagaimana konsumen berpersepsi terhadap pada suatu activity pemasaran yang dilakukan perusahaan. Identitas moral merupakan karakteristik seseorang yang skema moralnya akan sangat relevan dengan diri mereka sendiri, sebagai representasi kognitif yang terorganisir akan sifat moral dan kebajikan. Identitas moral berkaitan dengan segala sesuatu yang ada kaitannya dengan kognitif seseorang yang mendasari dirinya dalam mengambil keputusan. Sedangkan konsep spiritualitas dapat diasumsikan sebagai pencarian pribadi dalam memahami jawaban atas pertanyaan tentang kehidupan. Seseorang dengan derajat spiritualitas yang lebih tinggi akan cenderung memiliki tingkat komitmen yang lebih tinggi terhadap etika dan keyakinan moral.

\section{Kesimpulan}

Ethics dapat dikaji secara komprehensif dari beragam perspektif, baik dari sudut pandang perusahaan melalui marketing ethics, maupun dari sudut pandang konsumen melalui Consumer ethics atau ethical consumer. Diskusi mengenai marketing ethics lebih dominan pada perspektif positive ethics dibandingkan normative ethics, sehingga memunculkan gap yang berpotensi untuk dibahas lebih lanjut secara lebih komprehensif. Pandangan filosofis dari ethics bersifat normatif dan berfokus pada nilai, sehingga akan terkait dengan justifikasi mengapa standar etika tertentu dapat diimplementasikan pada suatu praktek tertentu. Dalam konteks pemasaran internasional, pemasar perlu sangat berhati-hati akan perbedaan culture yang ada di tiap negara, terkait ethics. Implementasi strategi perusahaan akan ethics ini juga perlu selaras dengan nilai-nilai ethics, identitas moral, dan spiritualitas konsumen.

\section{Daftar Pustaka}

Carlos J. Rodriguez-Rad, Encarnacion Ramos-Hidalgo, (2018) "Spirituality, consumer ethics, and sustainability: the mediating role of moral identity", Journal of Consumer Marketing, Vol. 35 Issue: 1, pp.51-63, https://doi.org/10.1108/JCM-12-2016-2035 
Hunt, S. D. (2019). The ethics of branding, customer-brand relationships, brand-equity strategy, and branding as a societal institution. Journal of Business Research, 95, 408416. https://doi.org/10.1016/j.jbusres.2018.07.044

Javalgi, R.G. \& Russell, L.T.M. (2018). International Marketing Ethics: A Literature Review and Research Agenda. J Bus Ethics, 148, 703-720. https://doi.org/10.1007/s10551-015-2958-9.

Laczniak, G. R., \& Murphy, P. E. (2018). The role of normative marketing ethics. Journal of Business Research, 95, 401 - 407. https://doi.org/10.1016/j.jbusres.2018.07.036 